\title{
Dynamic Behaviors and the Equivalent Realization of a Novel Fractional-Order Memristor-Based Chaotic Circuit
}

\author{
Ningning Yang $\mathbb{D},,^{1,2}$ Cheng $X u\left(\mathbb{D},,^{2}\right.$ Chaojun $W u\left(\mathbb{D},{ }^{3}\right.$ Rong Jia $\mathbb{D}^{1,2}$ and Chongxin Liu ${ }^{4}$ \\ ${ }^{1}$ State Key Laboratory Base of Eco-Hydraulic Engineering in Arid Area, Xi'an University of Technology, Xi'an 710048, China \\ ${ }^{2}$ Institute of Water Resources and Hydro-Electric Engineering, Xi'an University of Technology, Xi'an 710048, China \\ ${ }^{3}$ College of Electronics and Information, Xi'an Polytechnic University, Xi'an 710048, China \\ ${ }^{4}$ School of Electrical Engineering, Xi'an Jiaotong University, Xi'an 710049, China
}

Correspondence should be addressed to Cheng Xu; xucheng93@stu.xaut.edu.cn and Chaojun Wu; chaojun.wu@stu.xjtu.edu.cn

Received 30 May 2018; Revised 26 August 2018; Accepted 17 September 2018; Published 2 December 2018

Academic Editor: Chittaranjan Hens

Copyright (C) 2018 Ningning Yang et al. This is an open access article distributed under the Creative Commons Attribution License, which permits unrestricted use, distribution, and reproduction in any medium, provided the original work is properly cited.

\begin{abstract}
This paper proposed a novel fractional-order memristor-based chaotic circuit. A memristive diode bridge cascaded with a fractional-order RL filter constitutes the generalized fractional-order memristor. The mathematical model of the proposed fractional-order chaotic circuit is established by extending the nonlinear capacitor and inductor in the memristive chaotic circuit to the fractional order. Detailed theoretical analysis and numerical simulations are carried out on the dynamic behavior of the proposed circuit by investigating the stability of equilibrium points and the influence of circuit parameters on bifurcations. The results show that the order of the fractional-order circuit has a great influence on the dynamical behavior of the system. The system may exhibit complicated nonlinear dynamic behavior such as bifurcation and chaos with the change of the order. The equivalent circuits of the fractional-order inductor and capacitor are also given in the paper, and the parameters of the equivalent circuits are solved by an undetermined coefficient method. Circuit simulations of the equivalent fractionalorder memristive chaotic circuit are carried out in order to validate the correctness of numerical simulations and the practicability of using the integer-order equivalent circuit to substitute the fractional-order element.
\end{abstract}

\section{Introduction}

Since memristor was first postulated by Leon O. Chua in 1971 [1], the research on it has been a hot topic in research. Memristor is a nonlinear passive two-terminal component and represents the relationship between a charge and flux [2]. As the fourth fundamental circuit element besides the resistor, inductor, and capacitor, memristor has many unique features that other elements do not have. It can remember its history resistance so be known as a contraction of "memory resistor." The resistance of memristor depends on the magnitude, direction, and duration of the voltage applied to it [3]. In recent years, memristor has been widely used in many fields such as resistive random access memory (RRAM) $[4,5]$, neural networks [6-8], signal processing [9], chaotic and control systems [10], and sample recognition $[7,11]$.
The fingerprint of the memristor is that the loci in the voltage-current plane exhibit a pinched hysteresis loop which always passes through the origin when driven by any periodic input voltage source or current source [12]. Based on the above statement, a class of diode bridge circuits can be described as generalized memristors because they have been proved to satisfy the fingerprint of a memristor [13-19]. It is proved that an elementary electronic circuit consisting of a full-wave rectifier and a second-order RLC filter has memory properties [13]. Removing the resistor, another diode bridge circuit cascaded with a second-order filter containing an inductor and a capacitor can also constitute a generalized memristor [14]. Replacing the second-order filter with a firstorder parallel RC filter or a series first-order RL filter, a newly generalized memristor is realized, which reduces to a nonlinear fundamental element [15-17]. Recently, an improved memristive diode bridge circuit was put forward comprising 
four diodes and an inductor, which has a much simpler circuit realization $[18,19]$.

Due to the nonlinear characteristics of the memristor, chaotic oscillations can easily emerge. Replacing the Chua's diode in the canonical Chua's oscillator with a memristor, a memristor-based chaotic circuit was implemented in 2008 [20], which is known as the first combination of memristor and chaotic circuit. Since then, the study of memristor chaotic circuits has been widely undertaken [21-27]. A simple memristor chaotic circuit is proposed in paper [23], in which the inductor and capacitors are connected in series and one capacitor cascaded with a memristor. In paper [24], a memristor, an inductor, a capacitor, and a linear negative resistor constitute a chaotic circuit, and paper [25] puts forward a simplest chaotic circuit which has only three circuit elements: a linear passive inductor, a linear passive capacitor, and a nonlinear active memristor.

On the other hand, fractional calculus, a more than 300year-old mathematical subject, can describe a real object more accurately than the classical "integer" methods [28]. In addition, due to the introduction of extra adjustable parameters, the fractional-order model will increase the degree of freedom. What is worth mentioning is that the principle of fractional calculus is based on the memory property of the fractional-order integral or derivative [29], so the connection between fractional calculus and memristor is straightforward, the memristor can be extended to fractional order as well. In paper [30], a fractional-order memristor model was applied to the Chua's oscillator for the first time, which constructed a fractional-order memristor-based chaotic circuit. Paper [31] proposed a fractional-order generalized memristor which consists of four diodes cascaded with a fractional-order parallel RC filter (the order is between 0 and 1) and established a fractional-order chaotic circuit by replacing the traditional Chua's diode with the proposed memristor. The fractional-order capacitor and inductor are implemented by the corresponding unit circuits. Not only numerical simulations were carried out but also equivalent circuits were realized in the paper.

This paper is organized as follows. Section 2 briefly introduces the fundamental of fractional calculus and constructs a generalized memristor based on a fractionalorder series RL filter and then establishes a fractionalorder memristive chaotic circuit. In Section 3, detailed theoretical analysis and numerical simulations are carried out on the dynamic behavior of the proposed circuit by investigating the stability of equilibrium points and the influence of system parameters on bifurcations. In Section 4, the equivalent circuits of fractional-order inductor and capacitor are implemented, and circuit simulations of the realized fractional-order memristive chaotic circuit are carried out. Section 5 concludes this article with some additional remarks.

\section{Fractional-Order Memristive Chaotic Circuit}

2.1. Fundamentals of Fractional Calculus. Fractional calculus, as a generalization of integration and differentiation to integer order, can more accurately characterize the properties of actual objects. The fundamental integral-differential operator ${ }_{n} D_{t}^{\lambda}$ is defined as $[32,33]$

$$
{ }_{n} D_{t}^{\lambda}= \begin{cases}\frac{d^{\lambda}}{d t^{\lambda}}, & \lambda>0, \\ 1, & \lambda=0, \\ \int_{n}^{t}(d \tau)^{-\lambda}, & \lambda<0,\end{cases}
$$

where $n$ and $t$ are the bounds of the operation and $\lambda$ is the order.

There are three equivalent definitions used for the general fractional differentiation known as the GrünwaldLetnikov (GL) definition, the Riemann-Liouville (RL) definition, and the Caputo definition. The Caputo definition is more convenient for initial condition problems because its physical meaning is clear [34-36]. In this work, we will use the differential conformal transformation based on Caputo's derivatives. The Caputo definition can be written as

$$
{ }_{n}^{C} D_{t}^{\lambda} f(t)=\frac{1}{\Gamma(m-\lambda)} \int_{n}^{t} \frac{f^{(m)}(\tau)}{(t-\tau)^{\lambda-m+1}} d \tau, \quad m-1<\lambda<m,
$$

where $\Gamma(\cdot)$ is the gamma function and $\lambda$ is usually greater than zero [29]. The main advantage of Caputo's approach is that the initial conditions for fractional differential equations with Caputo derivatives are in the same form as for integer-order differential equations, and the Laplace transform of the Caputo derivative allows utilization of initial values of classical integer-order derivatives with known physical interpretations [33]. The Laplace transform of the $\lambda$ order Caputo differential operator is

$$
L\left\{{ }_{0}^{C} D_{t}^{\lambda} f(t)\right\}=s^{\lambda} F(s)-\sum_{k=0}^{m-1} s^{k}\left[\frac{d^{\lambda-1-k} f(t)}{d t^{\lambda-1-k}}\right]_{t=0},
$$

where $m$ is an integer and $\lambda \in(m-1, m)$. In this paper, we consider the zero initial conditions, so Laplace transform of Caputo's fractional derivative reduces to [37]

$$
L\left\{{ }_{0}^{C} D_{t}^{\lambda} f(t)\right\}=s^{\lambda} F(s) .
$$

In this case, the three well-known definitions of fractional derivatives are equivalent [38].

2.2. Fractional-Order Memristor Model. Paper [17] has demonstrated that a diode bridge circuit cascaded with an inductor and resistor in series satisfied the definition of a generalized memristor, whose equivalent circuit only contains six fundamental elements, which is depicted in Figure 1. Assuming the voltage across the generalized 


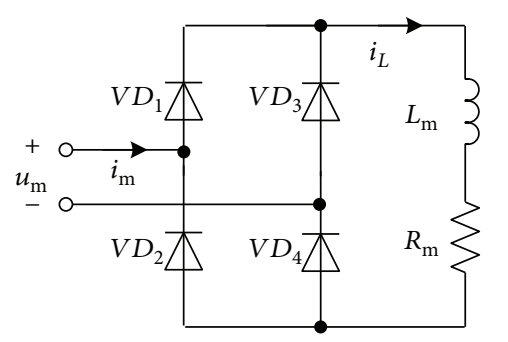

(a)

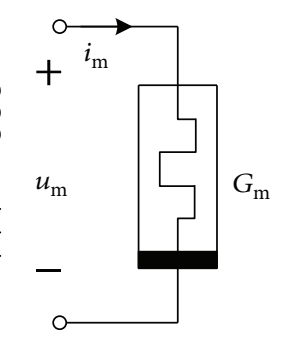

(b)
Figure 1: Generalized memristor and its circuit realization: (a) memristive diode bridge with series RL filter and (b) memristor symbol representation.

memristor is $u_{\mathrm{m}}$, the current flowing through the generalized memristor is $i_{\mathrm{m}}$, and the current passing through the inductor $L_{\mathrm{m}}$ is $i_{L}$, the mathematical model of the proposed generalized memristor circuit is established as

$$
\left\{\begin{array}{l}
\frac{d i_{L}}{d t}=\frac{u_{\mathrm{m}}}{L_{\mathrm{m}}}-\frac{R_{\mathrm{m}} i_{L}}{L_{\mathrm{m}}}-\frac{1}{\rho L_{\mathrm{m}}} \ln \left(\frac{\left(2 I_{S}+i_{L}\right) e^{\rho u_{\mathrm{m}}}}{2 I_{S} \cosh \left(\rho u_{\mathrm{m}}\right)}\right) \\
i_{\mathrm{m}}=\left(2 I_{S}+i_{L}\right) \tanh \left(\rho u_{\mathrm{m}}\right)
\end{array}\right.
$$

where $I_{S}$ and $\rho$ are diode parameters and $\rho=1 /\left(2 n V_{T}\right) . I_{S}, n$, and $V_{T}$ indicate the reverse saturation current, emission coefficient, and the thermal voltage of the diode, respectively. In this paper, diodes $1 \mathrm{~N} 4148$ are used for circuit simulations, and parameters of the diodes are presented as $I_{S}=2.682 \mathrm{nA}$, $n=1.836$, and $V_{T}=25 \mathrm{mV}$.

As nonlinear elements, inductors and capacitors can be extended to fractional order from the point of view of fractional calculus [29]. As a result, a fractional-order inductor-based generalized memristive circuit is realized by replacing the integer-order inductor $L_{\mathrm{m}}$ with a fractionalorder inductor $L_{\mathrm{m}}^{\lambda}$ and whose mathematical model can be expressed as

$$
\left\{\begin{array}{l}
\frac{d^{\lambda} i_{L}}{d t^{\lambda}}=\frac{u_{\mathrm{m}}}{L_{\mathrm{m}}^{\lambda}}-\frac{R_{\mathrm{m}} i_{L}}{L_{\mathrm{m}}^{\lambda}}-\frac{1}{\rho L_{\mathrm{m}}^{\lambda}} \ln \left(\frac{\left(2 I_{S}+i_{L}\right) e^{\rho u_{\mathrm{m}}}}{2 I_{S} \cosh \left(\rho u_{\mathrm{m}}\right)}\right), \\
i_{\mathrm{m}}=\left(2 I_{S}+i_{L}\right) \tanh \left(\rho u_{\mathrm{m}}\right) .
\end{array}\right.
$$

In order to verify whether the proposed fractional-order generalized memristor satisfied the three fingerprints of a memristor [39], numerical simulations are carried out using MATLAB software. The input voltage is given as a sinusoidal voltage $u_{\mathrm{m}}=A_{\mathrm{m}} \sin (2 \pi f t)$, and the parameters of the inductor and the resistor are $280 \mathrm{mH}$ and $580 \Omega$, respectively. Setting the fractional order $\lambda$ equals 0.95 , the relationship curves of the memristor input voltage and input current versus different frequencies are indicated in Figure 2(a), and the relationship curves with different amplitudes are demonstrated in Figure 2(b). The amplitude of input voltage in Figure $2(\mathrm{a})$ is set as $A_{\mathrm{m}}=4 \mathrm{~V}$, and the frequency of input voltage is $f=500 \mathrm{~Hz}$ in Figure 2(b). Moreover, the hysteresis loops with different orders are shown in Figure 2(c), in which theamplitude and frequency are set as $A_{\mathrm{m}}=4 \mathrm{~V}$ and $f=500 \mathrm{~Hz}$, respectively. It can be seen that the hysteresis loops pinched at the origin and the area of the pinched hysteresis loops decrease monotonically as the input voltage frequency increase when the frequency is greater than the critical value. Besides, the pinched hysteresis loop will shrink to a nonlinear single-valued function when the frequency tends to infinity. The areas of pinched hysteresis loops increase as the input voltage amplitude increase as well, as depicted in Figure 2(b). In addition, the pinched hysteresis loops indicated in Figure 2(c) demonstrate that the order of the fractional-order inductor can affect the dynamic characteristics of the memristor. It can be seen that the pinched hysteresis loops with different amplitudes are similar to each other (see Figure 2(b)), but the frequency and the order can bring about an important impact on the memristive characteristics (see Figures 2(a) and 2(c)).

2.3. Fractional-Order Memristor-Based Chaotic Circuit. After the realization of the fractional-order generalized memristor, we consider applying the proposed first-order generalized memristor to a classical Chua's circuit. By replacing the traditional Chua's oscillator with a fractional-order inductorbased memristor, a fractional-order memristive chaotic circuit is established, which is indicated in Figure 3. Since the practical inductor and capacitor can be extended to fractional order to better express its electricity characteristics, the capacitance and inductance used in this paper are all fractional order. Therefore, the circuit is composed of six elements which are a fractional-order inductor $L^{\lambda}$, two fractional-order capacitors $C_{1}^{\lambda}$ and $C_{2}^{\lambda}$, a fractional-order memristor $M^{\lambda}$, a linear passive resistor, and a negative conductance. Because the proposed fractional-order memristive Chua's circuit has four dynamic elements, there are four corresponding state variables, which are the voltages across the fractional-order capacitors $C_{1}^{\lambda}$ and $C_{2}^{\lambda} v_{1}$ and $v_{2}$, the current flowing through the fractional-order inductor $L^{\lambda} i_{3}$. The last one is the current passing through the fractional-order inductor $L_{\mathrm{m}}^{\lambda}$ in the fractional-order generalized memristor, $M^{\lambda} i_{L}$, as shown in (6), which can express the dynamic characteristics of the fractional-order generalized memristor $M^{\lambda}$. Utilizing Kirchhoff voltage law (KVL) and Kirchhoff current law (KCL), the characteristic equation of the fractional-order memristive Chua's circuit can be derived as

$$
\left\{\begin{array}{l}
\frac{d^{\lambda} v_{1}}{d t^{\lambda}}=\frac{v_{2}-v_{1}}{R C_{1}^{\lambda}}-\frac{i_{3}}{C_{1}^{\lambda}}, \\
\frac{d^{\lambda} v_{2}}{d t^{\lambda}}=\frac{v_{2}(R G-1)}{R C_{2}^{\lambda}}+\frac{v_{1}}{R C_{2}^{\lambda}}-\frac{\left(2 I_{S}+i_{L}\right) \tanh \left(\rho v_{2}\right)}{C_{2}^{\lambda}}, \\
\frac{d^{\lambda} i_{3}}{d t^{\lambda}}=\frac{v_{1}}{L^{\lambda}}, \\
\frac{d^{\lambda} i_{L}}{d t^{\lambda}}=\frac{v_{2}}{L_{\mathrm{m}}^{\lambda}}-\frac{R_{\mathrm{m}} i_{L}}{L_{\mathrm{m}}^{\lambda}}-\frac{1}{\rho L_{\mathrm{m}}^{\lambda}} \ln \left(\frac{\left(2 I_{S}+i_{L}\right) e^{\rho v_{2}}}{2 I_{S} \cosh \left(\rho v_{2}\right)}\right) .
\end{array}\right.
$$




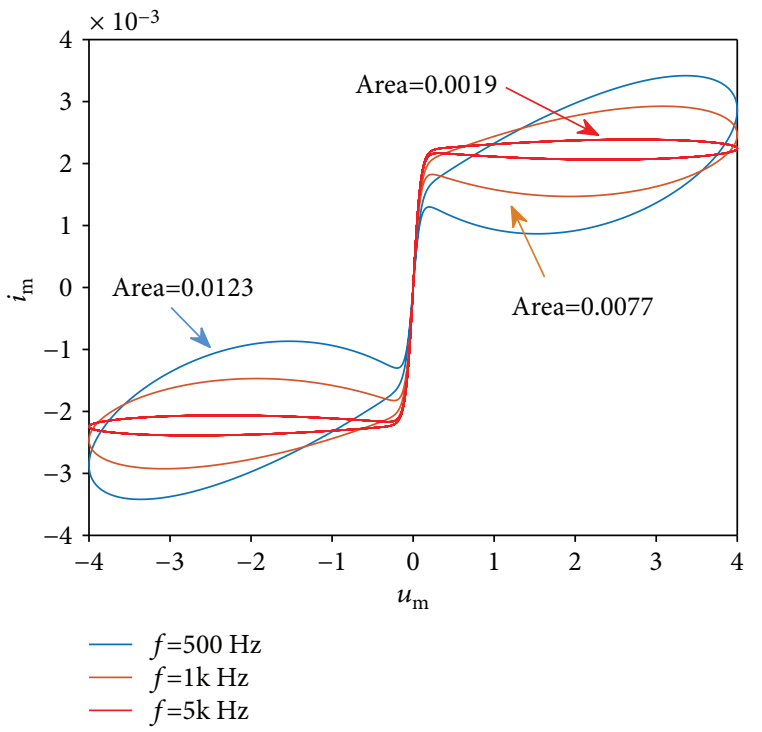

(a)

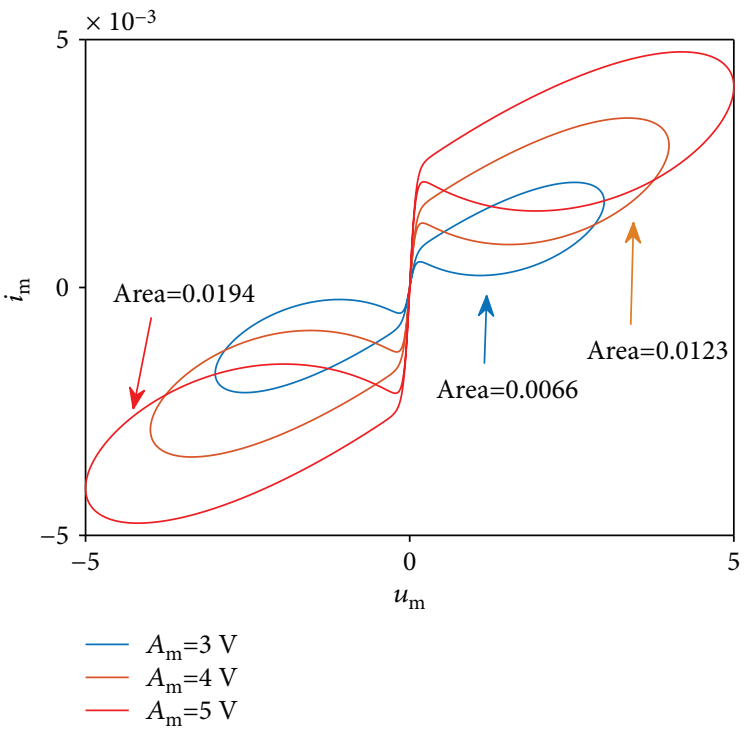

(b)

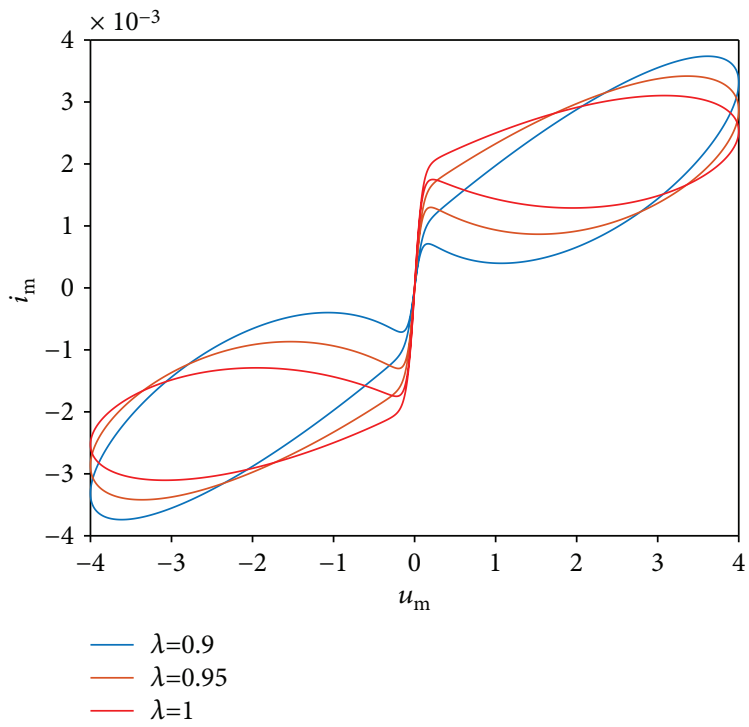

(c)

Figure 2: The hysteresis loops of the fractional-order memristor with different sinusoidal input voltages: (a) $A_{\mathrm{m}}=4 \mathrm{~V}$ and $\lambda=0.95$ with different frequencies, (b) $f=500 \mathrm{~Hz}$ and $\lambda=0.95$ with different amplitudes, and (c) $A_{\mathrm{m}}=4 \mathrm{~V}$ and $f=500 \mathrm{~Hz}$ with different orders.

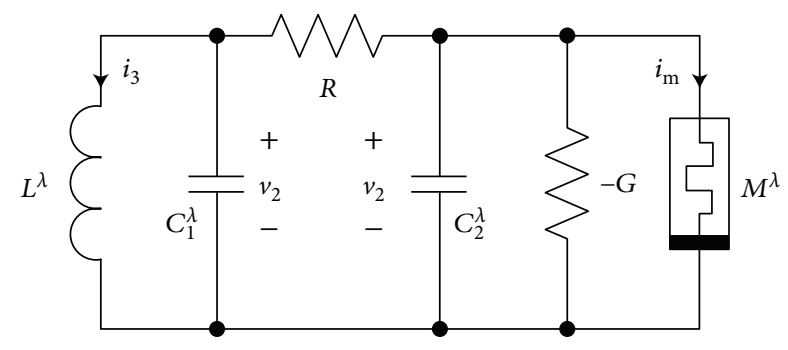

Figure 3: Fractional-order memristive Chua's circuit.

The model of the fractional-order memristive Chua's circuit is established in MATLAB, and simulations are carried out in numerical. Set capacitance $C_{1}^{\lambda}=100 \mathrm{nF}$, capacitance
$C_{2}^{\lambda}=10 \mathrm{nF}$, inductance $L^{\lambda}=12 \mathrm{mH}$, resistance $R=2 \mathrm{k} \Omega$, and conductance $G=0.6667 \mathrm{mS}$, and the parameters of the fractional-order generalized memristor are the same as that mentioned above. When the fractional order $\lambda$ is taken as 0.98 and the initial values of the state variables are selected as $v_{1}=0 \mathrm{~V}, v_{2}=0.01 \mathrm{~V}, i_{3}=0 \mathrm{~A}$, and $i_{L}=0 \mathrm{~A}$, the phase diagrams of the fractional-order memristive Chua's circuit are exhibited in Figure 4.

\section{Chaotic Dynamic Behavior of the Fractional- Order Memristive Chua's Circuit}

3.1. Equilibrium Points and Stability. In this section, equilibrium points and eigenvalues of the corresponding Jacobian 


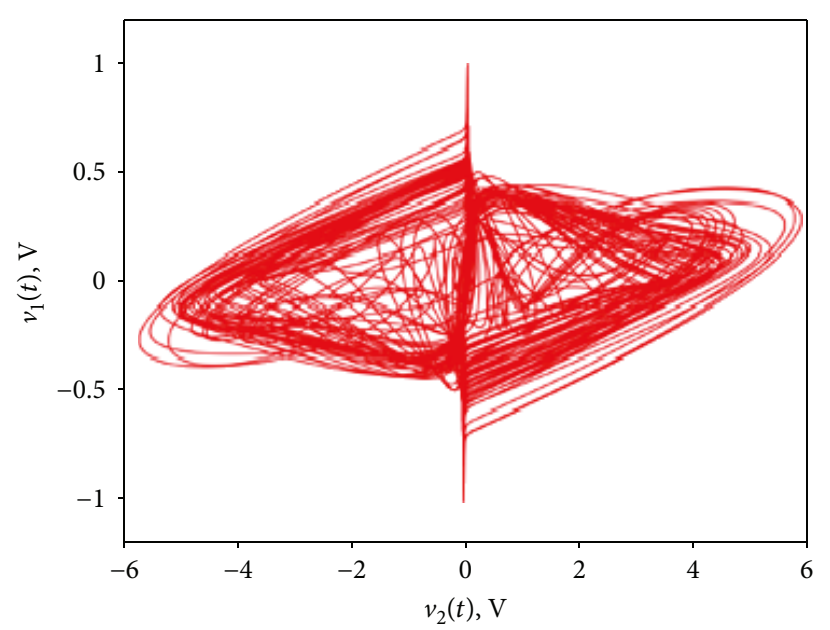

(a)

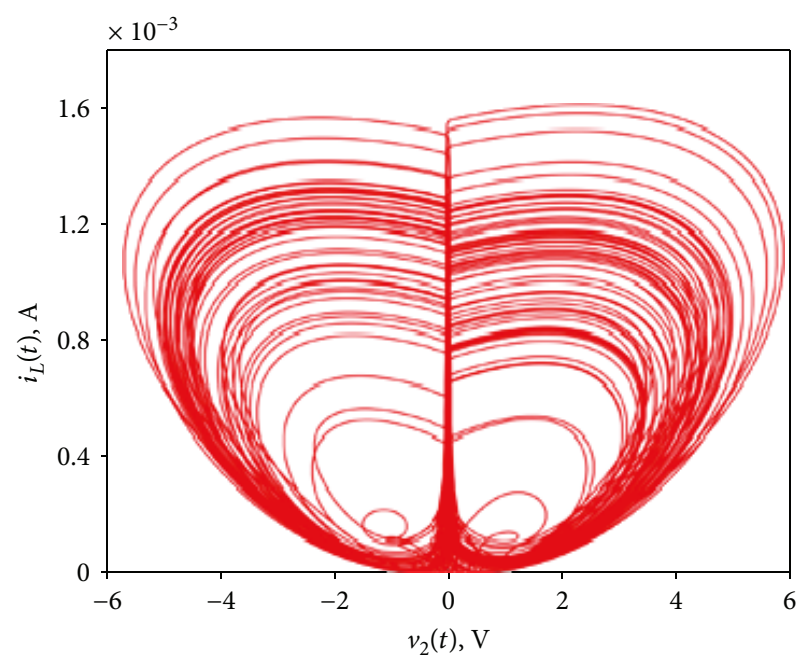

(c)

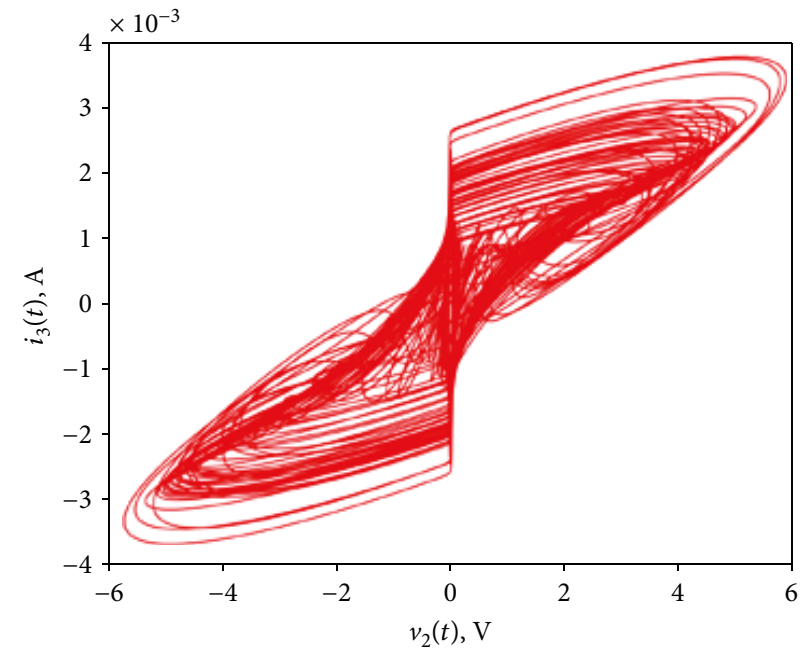

(b)

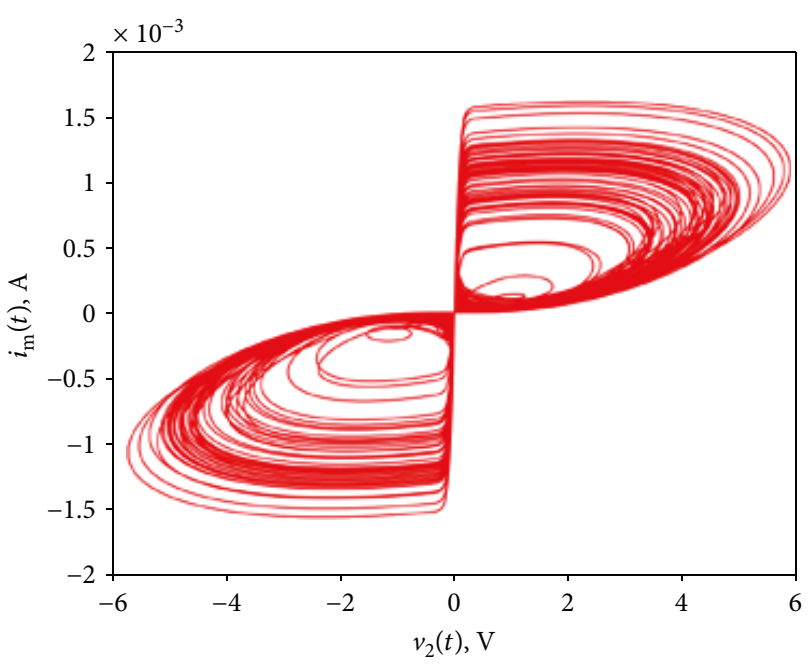

(d)

Figure 4: Phase diagrams of the fractional-order memristive Chua's circuit. Phase diagrams in the (a) $v_{2}(t)-v_{1}(t)$ plane, (b) $v_{2}(t)-i_{3}(t)$ plane, (c) $v_{2}(t)-i_{L}(t)$ plane, and (d) $v_{2}(t)-i_{\mathrm{m}}(t)$ plane.

matrix are calculated to qualitatively analyze the dynamic behavior of the proposed fractional-order memristive chaotic circuit. The equilibrium points of such a circuit can be obtained by solving the following equations:

$$
\left\{\begin{array}{l}
v_{1}=0, \\
v_{2}(R G-1)=R\left(2 I_{S}+i_{L}\right) \tanh \left(\rho v_{2}\right), \\
v_{2}=R_{\mathrm{m}} i_{L}+\frac{1}{\rho} \ln \left(\frac{\left(2 I_{S}+i_{L}\right) e^{\rho v_{2}}}{2 I_{S} \cosh \left(\rho v_{2}\right)}\right), \\
v_{2}=i_{3} R .
\end{array}\right.
$$

Obviously, $O_{1}=(0,0,0,0)$ is one equilibrium point of the fractional-order memristive Chua's circuit, but the analytic solutions of $v_{2}$ and $i_{L}$ cannot be computed in MATLAB, so we consider using the graphic analytic method to obtain the other equilibrium points [16]. The relationship between $v_{2}$ and $i_{L}$ can be written as

$$
\left\{\begin{array}{l}
v_{2}= \pm \frac{1}{\rho} \operatorname{acosh}\left(\frac{\left(2 I_{S}+i_{L}\right) e^{\rho R_{\mathrm{m}} i_{L}}}{2 I_{S}}\right) \\
i_{L}=\frac{(R G-1) v_{2}}{R \tanh \left(\rho v_{2}\right)}-2 I_{S}
\end{array}\right.
$$

Utilizing (9), we can draw two functions between $v_{2}$ and $i_{L}$; then the intersection coordinates of two functions can easily be obtained, as shown in Figure 5. Thus, the other two equilibrium points are obtained as $\mathrm{O}_{2}=(0$, $1.134,0.000567,0.000189)$ and $O_{3}=(0,-1.134,-0.000567$, $0.000189)$. 


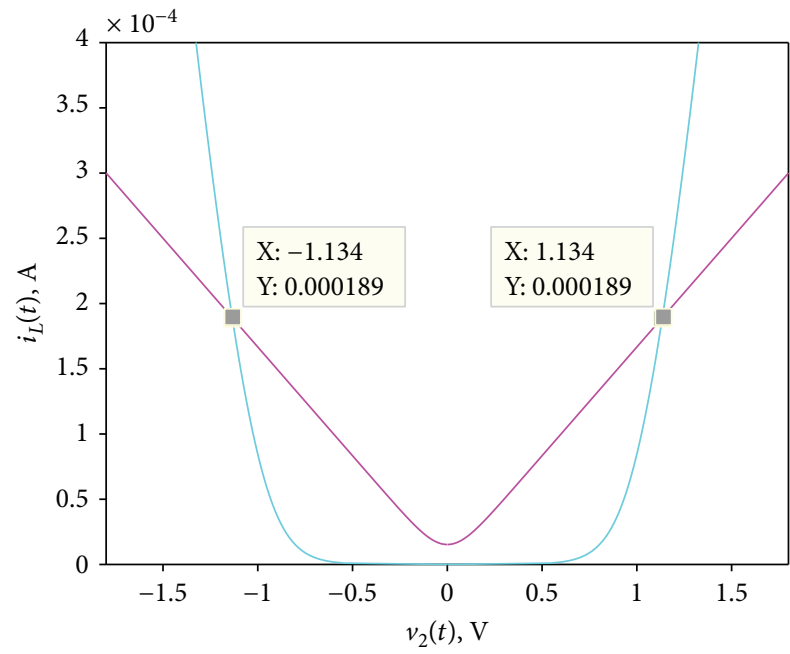

FIgURE 5: Two functions and their intersection points.

The Jacobian matrix of the characteristic (7) can be described as

$$
\left[\begin{array}{cccc}
-\frac{1}{R C_{1}^{\lambda}} & \frac{1}{R C_{1}^{\lambda}} & -\frac{1}{C_{1}^{\lambda}} & 0 \\
\frac{1}{R C_{2}^{\lambda}} & \Lambda_{1} & 0 & -\frac{\tanh \left(\rho v_{2}\right)}{C_{2}^{\lambda}} \\
\frac{1}{L^{\lambda}} & 0 & 0 & 0 \\
0 & \Lambda_{2} & 0 & -\frac{R_{\mathrm{m}}}{L_{\mathrm{m}}^{\lambda}}-\frac{1}{\rho L_{\mathrm{m}}^{\lambda}\left(2 I_{S}+i_{L}\right)}
\end{array}\right]
$$

where $\Lambda_{1}$ and $\Lambda_{2}$ can be expressed as

$$
\begin{aligned}
\Lambda_{1}= & \frac{R G-1}{R C_{2}^{\lambda}}+\frac{\rho}{C_{2}^{\lambda}}\left(2 I_{S}+i_{L}\right)\left(\tanh ^{2}\left(\rho v_{2}\right)-1\right) \\
\Lambda_{2}= & \frac{1}{L_{\mathrm{m}}^{\lambda}}-\frac{2 I_{S} e^{-\rho v_{2}} \cosh \left(\rho v_{2}\right)}{\rho L_{\mathrm{m}}^{\lambda}\left(2 I_{S}+i_{L}\right)} \\
& \cdot\left(\frac{\rho\left(2 I_{S}+i_{L}\right) e^{\rho v_{2}}}{2 I_{S} \cosh \left(\rho v_{2}\right)}-\frac{\rho\left(2 I_{S}+i_{L}\right) e^{\rho v_{2}} \sinh \left(\rho v_{2}\right)}{2 I_{S} \cosh ^{2}\left(\rho v_{2}\right)}\right)
\end{aligned}
$$

Then the eigenvalues at equilibrium points $O_{1,2,3}$ can be calculated as

$$
\begin{aligned}
O_{1}: \zeta_{1} & =-61,124,000, \\
\zeta_{2} & =20,000, \\
\zeta_{3,4} & =-4000 \pm 26,000 i, \\
O_{2,3}: \zeta_{1,2} & =-6106 \pm 26,054 i, \\
\zeta_{3,4} & =10,038 \pm 15,524 i .
\end{aligned}
$$

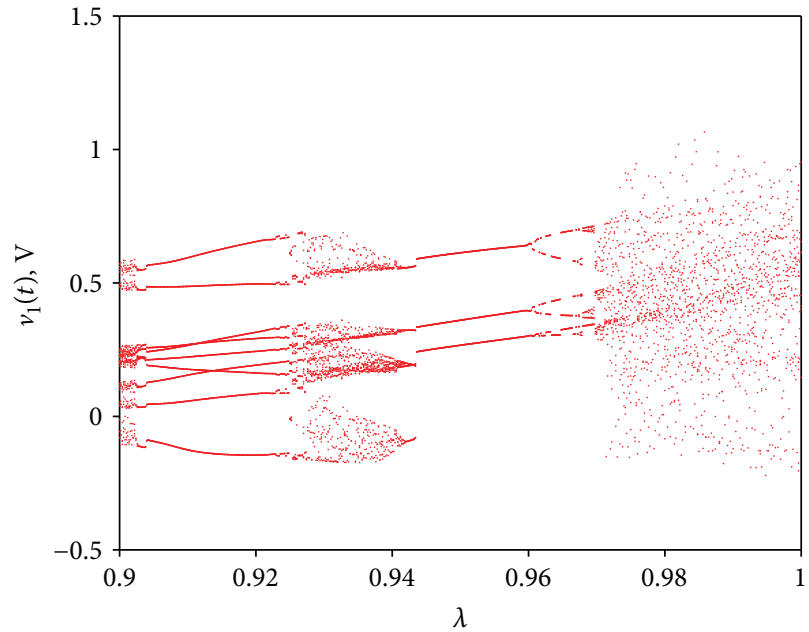

FIGURE 6: Bifurcation diagram of the fractional-order memristive chaotic circuit with the different order.

It can be seen that equilibrium point $O_{1}$ has a positive real root and equilibrium point $\mathrm{O}_{2,3}$ have two complex conjugate roots with the positive real part. As a result, the system is unstable and has chaotic attractors.

3.2. Bifurcation with the Changing of Order $\lambda$. The fractionalorder models can increase the flexibility and degrees of freedom by means of the fractional parameters. In this section, the change of the fractional order $\lambda$ is applied in the fractional-order memristive Chua's circuit, and the influence of the order on the performance of the fractional-order memristive chaotic circuit is discussed. Taking the same circuit parameters as mentioned above and the initial conditions are set as $(0 \mathrm{~V}, 0.01 \mathrm{~V}, 0 \mathrm{~A}, 0 \mathrm{~A})$, the bifurcation diagram of the fractional-order chaotic circuit described in (7) can be obtained, as depicted in Figure 6. It shows that the dynamical behaviors of the system can be divided into three states: periodic state, bifurcation, and chaos. The system has two blocks of chaos around $\lambda=0.93$ and $\lambda=0.99$ when the order $\lambda$ varies from 0.9 to 1 . With the increase of the order, the system enters into the chaotic state from the periodic state abruptly when $\lambda>0.92$. However, the chaotic behavior does not exist for a long time; the system runs back to the periodic state when order $\lambda$ is just over 0.94 . When the order is higher than 0.97 , the system enters into chaos once more. Furthermore, the system displays complicated nonlinear dynamic behavior such as bifurcation and chaos when order $\lambda$ is greater than 0.96 . In order to further illustrate the influence of the order on the dynamic behaviors of the system, a comparative analysis is carried out. The phase diagrams of the fractional-order memristive Chua's circuit when order equals to 0.955 and 0.965 are indicated in Figure 7 . It can be seen that the circuit is a single cycle when $\lambda=0.955$, but when $\lambda=0.965$, the circuit has two or more cycles, bifurcation occurs, which corresponds well with the results in the bifurcation diagram as shown in Figure 6. In addition, it is worth noting that the orbits of state variable $v_{1}(t)$ with order 


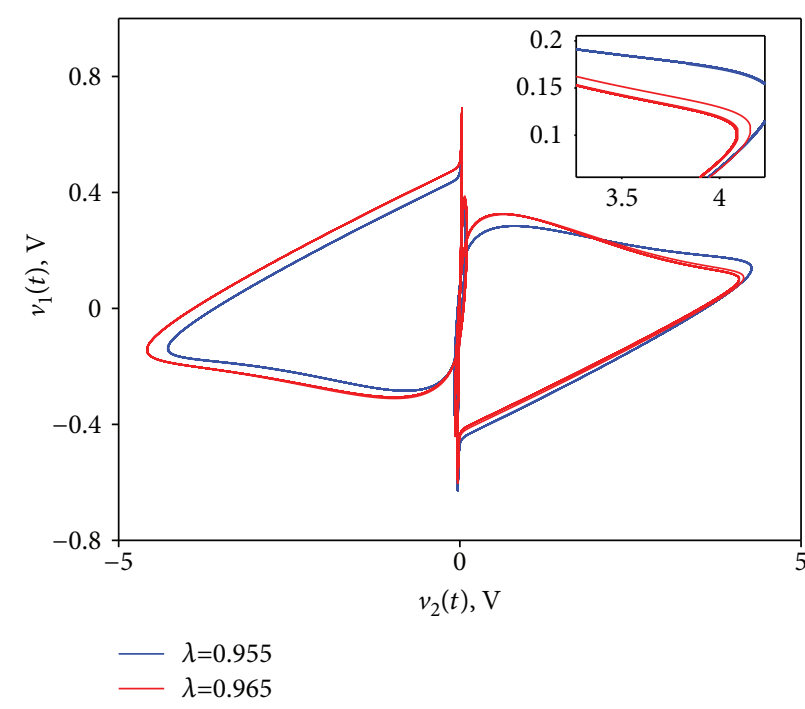

(a)

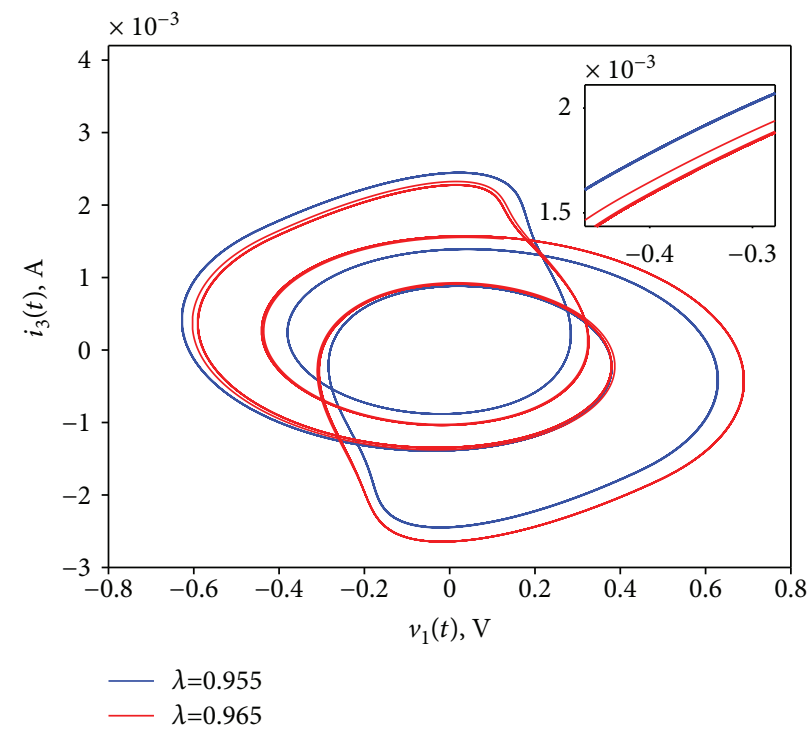

(b)

Figure 7: The phase diagrams of the fractional-order memristive Chua's circuit with the different order.

$\lambda$ do not change smoothly with order $\lambda$, which is different from most of other bifurcation diagrams. From the above analysis, we know that different orders will cause different dynamical behaviors of the memristive chaotic circuit, such as bifurcation and chaos, which indicates that the order plays a significant role in the performance of the fractional-order memristive chaotic circuit.

3.3. Bifurcation with the Changing of Inductor $L^{\lambda}$. The bifurcation diagram of $v_{2}(t)$ with inductor $L^{\lambda}$ is depicted in Figure 8.

The orbits painted in red indicate the integer-order system with order $\lambda=1$, and the orbits painted in blue express the fractional-order system whose order $\lambda=0.92$. For the integer-order system, as the increase of inductor value, the orbits of the memristive Chua's circuit start from the periodic state and then enter into chaos abruptly. After increasing for a period of time, the system returns back to periodic behavior. The phenomenon is not the same as that in the fractional-order system. The inductance value required for the fractional-order system to enter into chaotic behavior is larger than that of the integer-order system. Moreover, the fractional-order system is still in chaos when the inductance is greater than $33 \mathrm{mH}$, but the orbits are in a periodic state for the integer-order systems. In order to verify whether the theoretical analysis of the bifurcation diagram is correct, the phase diagrams of the integer-order system and fractionalorder system with order $\lambda=0.92$ are given in Figure 9 when inductance $L^{\lambda}=20 \mathrm{mH}$ and $L^{\lambda}=40 \mathrm{mH}$, respectively. It can be seen that the results of the phase diagrams well demonstrate the correctness of the bifurcation diagram. The integer-order system is chaotic but the fractional-order system is periodic when inductance value $L^{\lambda}=20 \mathrm{mH}$. Meanwhile, the integer-order system has a periodic behavior

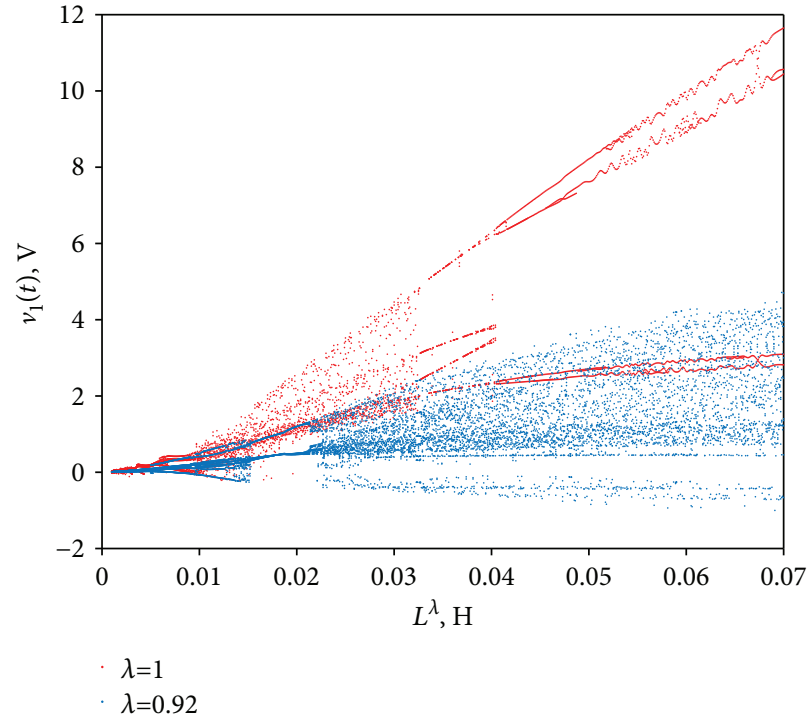

FIGURE 8: Bifurcation diagrams of the fractional-order memristive chaotic circuit and integer-order memristive chaotic circuit with different inductance $L^{\lambda}$.

but the fractional-order system has a chaotic behavior when inductance value $L^{\lambda}=40 \mathrm{mH}$.

\section{Circuit Realization of the Fractional-Order Memristive Chaotic Circuit}

In this section, equivalent circuits are used to simulate the fractional-order memristive chaotic circuit. Since the inductor and capacitor can be extended to fractional order, the Oustaloup filter algorithm is used to obtain the approximate 

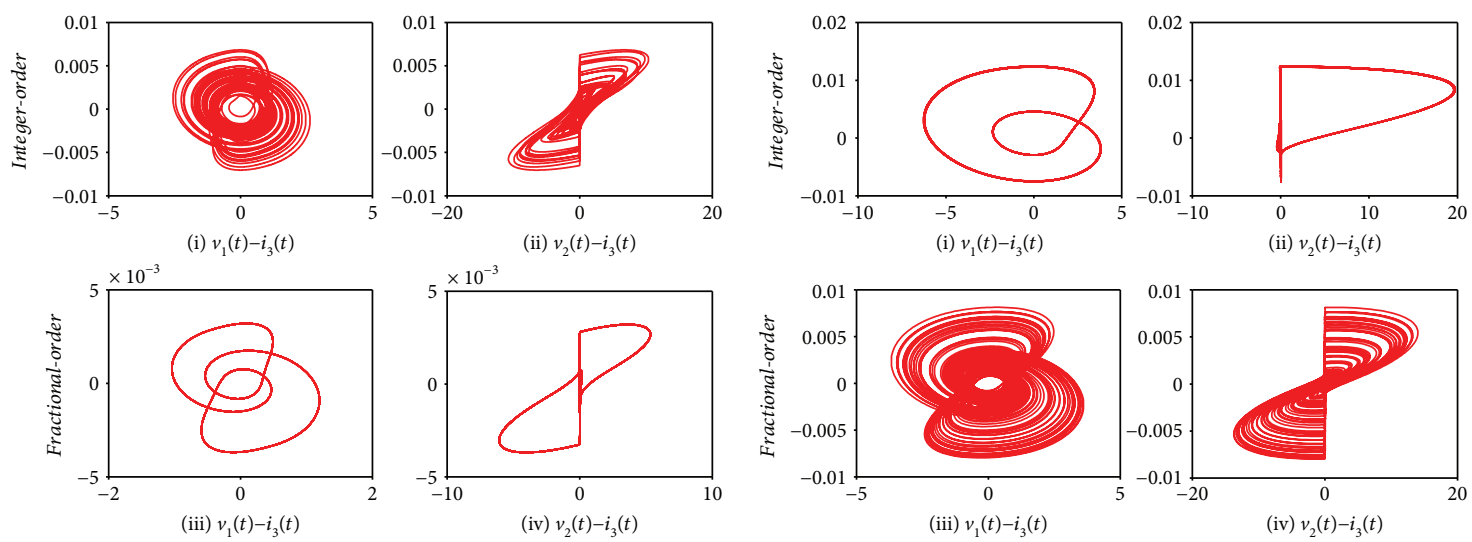

(a)

(b)

Figure 9: Phase diagrams of the integer-order system and fractional-order system: (a) $L^{\lambda}=20 \mathrm{mH}$ and (b) $L^{\lambda}=40 \mathrm{mH}$.

transfer function of fractional Laplace transform operator $s^{\lambda}$ [40], then simplifying the transfer functions into zeropole forms and using chain circuits to realize the equivalent circuit of fractional-order inductor and capacitor [41].

4.1. Equivalent Circuit of Fractional-Order Generalized Memristor. The fractional Laplace transform operator of inductor in fractional-order generalized memristor can be physically realized using the RL chain circuits in Figure 10. The transfer function of the fractional-order inductor can be approximately expressed as

$$
\frac{1}{L} s^{-\lambda}=\sum_{i=1}^{n} \frac{1 / L_{i}}{\left(s+R_{i} / L_{i}\right)}+\frac{1}{R_{0}}
$$

where $\lambda$ is the order of the fractional-order inductor. Selecting $L=280 \mathrm{mH}, \lambda=0.95,0.98$ and $n=7$, resistance and inductance can be calculated by the method of undetermined coefficients. The parameters of the equivalent chain circuit of fractional-order inductor are listed in Tables 1 and 2. The magnitude and phase of the ideal $1 /$ $\left(L s^{\lambda}\right)$ and 7 th order Oustaloup approximation and fractance circuit approximation with $L=280 \mathrm{mH}$ and order $\lambda=0.95,0.98$ are presented in Figure 11. From the figure, we observe that the approximation is relatively good from $10^{-1} \mathrm{~Hz}$ to $10^{5} \mathrm{~Hz}$.

\subsection{Equivalent Circuit of Fractional-Order Memristive Chua's} Circuit. After realizing the equivalent circuit of fractionalorder inductor, we consider using the same method to achieve the equivalent circuit of the fractional-order capacitor. The approximate equivalence of the fractional-order capacitor can be actualized utilizing RC ladder topologies, as shown in Figure 12. The transfer function of the RC ladder network is expressed as

$$
\frac{1}{C} s^{-\lambda}=\sum_{i=1}^{n} \frac{1 / C_{i}}{\left(s+1 / R_{i} C_{i}\right)}+R_{0} .
$$

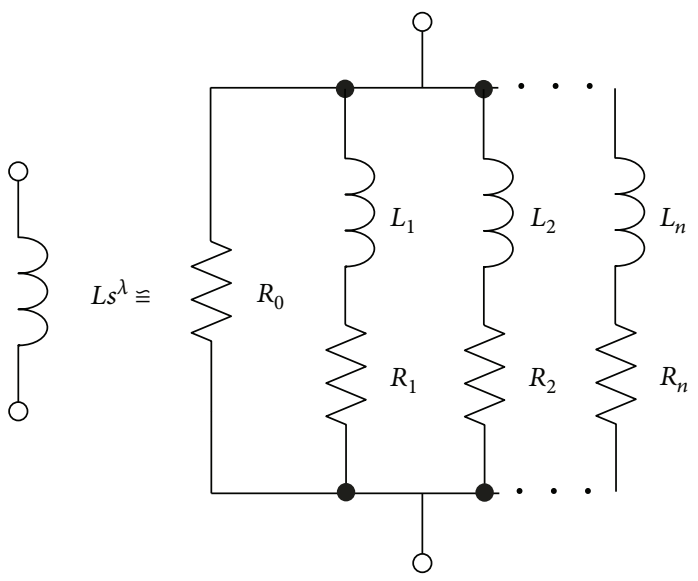

FIGURE 10: Equivalent chain circuit of fractional-order inductor.

In consideration of capacitors $C_{1}^{\lambda}=100 \mathrm{nF}$ and $C_{2}^{\lambda}=10$ $\mathrm{nF}$ in the fractional-order memristive Chua's circuit, choosing $\lambda=0.98$ and $n=7$, resistance and capacitance can be calculated as well, as listed in Tables 3 and 4 . The bode diagram of the ideal $1 /\left(C s^{\lambda}\right)$ and 7 th order Oustaloup approximation and fractance circuit approximation with $C^{\lambda}=10 \mathrm{nF}$ and $100 \mathrm{nF}$ and order $\lambda=0.98$ is indicated in Figure 13. It can be seen that the approximation is pretty good from $10^{-2} \mathrm{~Hz}$ to $10^{5} \mathrm{~Hz}$. The chain equivalent parameters of fractionalorder inductor $L^{\lambda}$ in the fractional-order memristive Chua's circuit can be calculated as well, as listed in Tables 5 and 6 , and the bode diagram shows a good approximation from $10^{-2} \mathrm{~Hz}$ to $10^{5} \mathrm{~Hz}$, as shown in Figure 14 . Thus, the equivalent circuit of the fractional-order memristive Chua's circuit has been completed as shown in Figure 15, which has four equivalent circuit units, and then the circuit simulation can be carried out on the fractional-order memristive equivalent circuit.

4.3. Circuit Simulations of the Fractional-Order Memristive Equivalent Circuit. In this section, we consider utilizing PSpice to simulate the fractional-order memristive equivalent 
TABLE 1: The resistance parameters of the equivalent chain circuit of fractional-order inductor.

\begin{tabular}{lcccccccc}
\hline$\lambda$ & $R_{0}(\Omega)$ & $R_{1}(\Omega)$ & $R_{2}(\Omega)$ & $R_{3}(\Omega)$ & $R_{4}(\Omega)$ & $R_{5}(\Omega)$ & $R_{6}(\Omega)$ & $R_{7}(\Omega)$ \\
\hline 0.95 & $1.25 e 6$ & $7.74 e 4$ & 964.42 & 12.14 & $1.53 e-1$ & $1.92 e-3$ & $2.52 e-6$ & $7.76 e-1$ \\
0.98 & $2.03 e 6$ & $2.55 e 5$ & $2.77 e 3$ & 30.39 & $3.33 e-1$ & $3.65 e-3$ & $1.78 e-6$ & $4.18 e-1$ \\
\hline
\end{tabular}

TABLE 2: The inductance parameters of the equivalent chain circuit of fractional-order inductor.

\begin{tabular}{llllllll}
\hline$\lambda$ & $L_{1}(\mathrm{H})$ & $L_{2}(\mathrm{H})$ & $L_{3}(\mathrm{H})$ & $L_{4}(\mathrm{H})$ & $L_{5}(\mathrm{H})$ & $L_{6}(\mathrm{H})$ & 0.4440 \\
\hline 0.95 & 0.6896 & 0.8595 & 1.0820 & 1.3621 & 1.7147 & $1.3688 e 5$ \\
0.98 & 2.4385 & 2.6473 & 2.9025 & 3.1825 & 3.4893 & 0.3367 & $7.9025 e 4$ \\
\hline
\end{tabular}

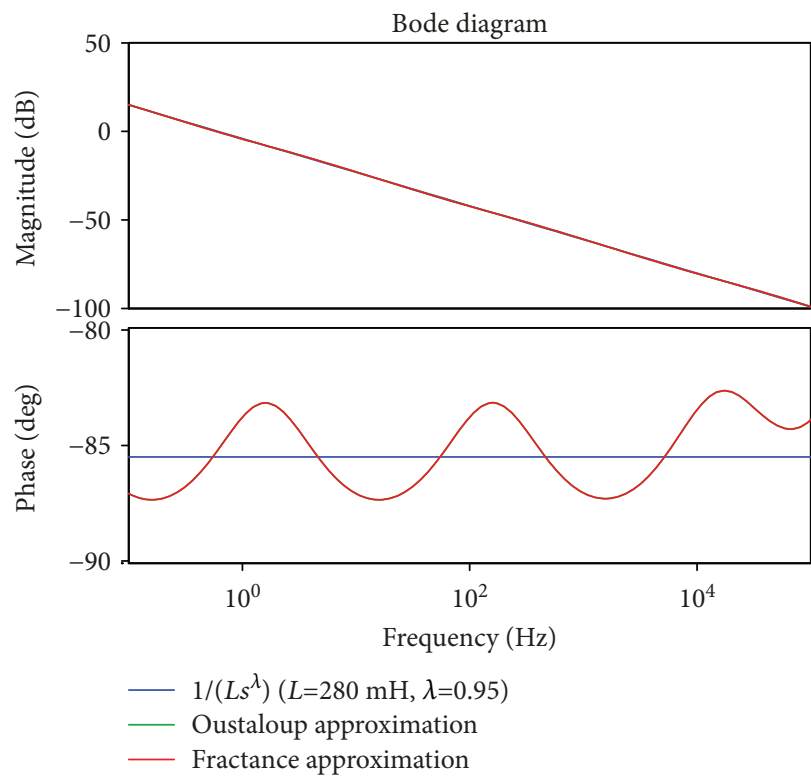

(a)

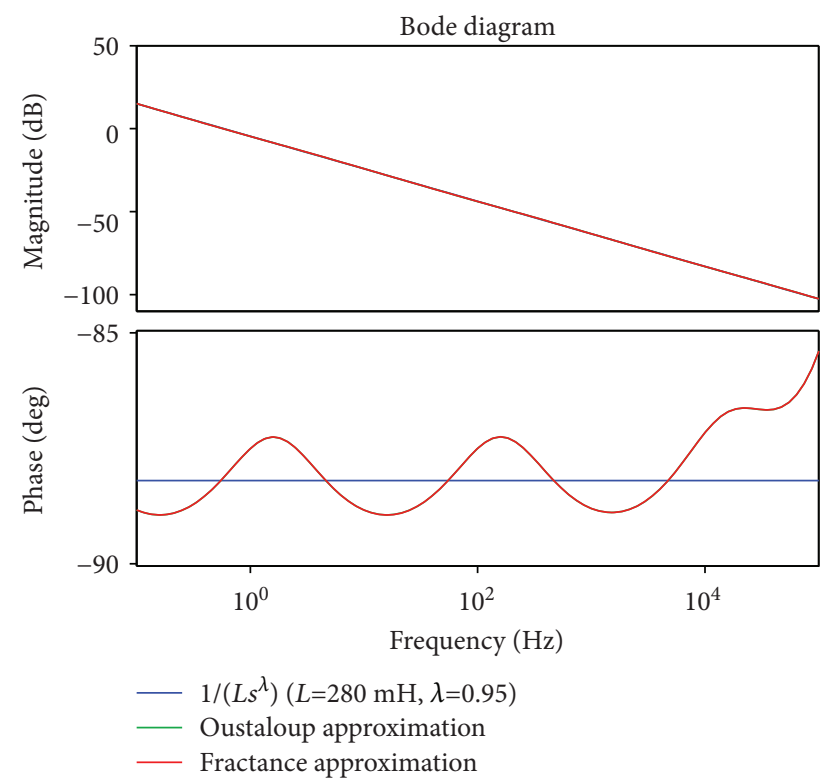

(b)

FIGURE 11: Bode diagram of Oustaloup approximation and fractance circuit approximation.

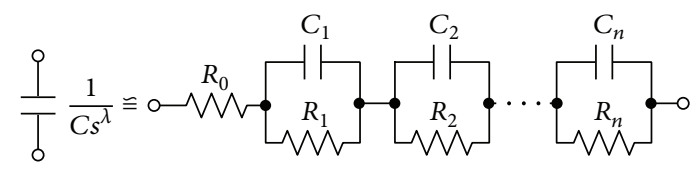

FIGURE 12: Equivalent ladder circuit of the fractional-order capacitor.

circuit. Considering order $\lambda=0.98$, the parameters of resistance $R_{\mathrm{m}}$ and diodes in fractional-order generalized memristor are the same as mentioned above, and fractional-order inductor $L_{\mathrm{m}}=280 \mathrm{mH}$ is realized by a chain unit, whose equivalent parameters are listed in Tables 1 and 2 . In addition, resistance $R$ and negative conductance $-G$ in the fractional-order memristive chaotic circuit are constant, while fractional-order capacitance $C_{1}^{\lambda}=100 \mathrm{nF}$ and $C_{2}^{\lambda}=$ $10 \mathrm{nF}$ and fractional-order inductance $L^{\lambda}=12 \mathrm{mH}$ are implemented by corresponding equivalent circuits, whose parameters are given in Tables 3-6. Thus, an equivalent circuit of the fractional-order memristor-based fractional- order Chua's circuit is achieved. Figure 16 shows the phase diagrams of the realized fractional-order memristive Chua's circuit by PSpice, and the results well verify the correctness of numerical simulations and the practicability of the fractional-order equivalent circuit.

\section{Conclusions}

In this paper, a fractional-order memristor-based chaotic circuit is presented. The inductor in generalized memristor and the capacitors and inductors in the memristive chaotic circuit are all fractional order. Firstly, the mathematical model of fractional-order inductor-based generalized memristor is established, and then the characteristic equations of the fractional-order memristive chaotic circuit are derived. After that, theoretical analysis and numerical simulations are carried out such as the analysis of equilibrium point and stability and the influence of the order on the stability of the system. The results show that the fractional-order circuit exhibits different dynamic behaviors such as 
TABLE 3: The resistance parameters of the equivalent ladder circuit of the fractional-order capacitor.

\begin{tabular}{lcccccccc}
\hline$C^{\lambda}(\mathrm{nF})$ & $R_{0}(\Omega)$ & $R_{1}(\Omega)$ & $R_{2}(\Omega)$ & $R_{3}(\Omega)$ & $R_{4}(\Omega)$ & $R_{5}(\Omega)$ & $R_{6}(\Omega)$ & $R_{7}(\Omega)$ \\
\hline 10 & 13.80 & 109.66 & $1.01 e 4$ & $9.21 e 5$ & $8.40 e 7$ & $7.66 e 9$ & $1.57 e 13$ & $6.70 e 7$ \\
100 & 1.38 & 10.97 & $1.01 e 3$ & $9.21 e 4$ & $8.40 e 6$ & $7.66 e 8$ & $1.57 e 12$ & $6.70 e 6$ \\
\hline
\end{tabular}

TABLE 4: The capacitance parameters of the equivalent ladder circuit of the fractional-order capacitor.

\begin{tabular}{lccccccc}
\hline$C^{\lambda}(\mathrm{nF})$ & $C_{1}(\mu \mathrm{F})$ & $C_{2}(\mu \mathrm{F})$ & $C_{3}(\mu \mathrm{F})$ & $C_{4}(\mu \mathrm{F})$ & $C_{5}(\mu \mathrm{F})$ & $C_{6}(\mu \mathrm{F})$ & $C_{7}(\mu \mathrm{F})$ \\
\hline 10 & $8.71 e-2$ & $9.45 e-2$ & $1.04 e-1$ & $1.14 e-1$ & $1.25 e-1$ & $1.20 e-2$ \\
100 & $8.71 e-1$ & $9.45 e-1$ & 1.04 & 1.14 & 1.25 & $1.20 e-1$ & $2.82 e 3$ \\
\hline
\end{tabular}

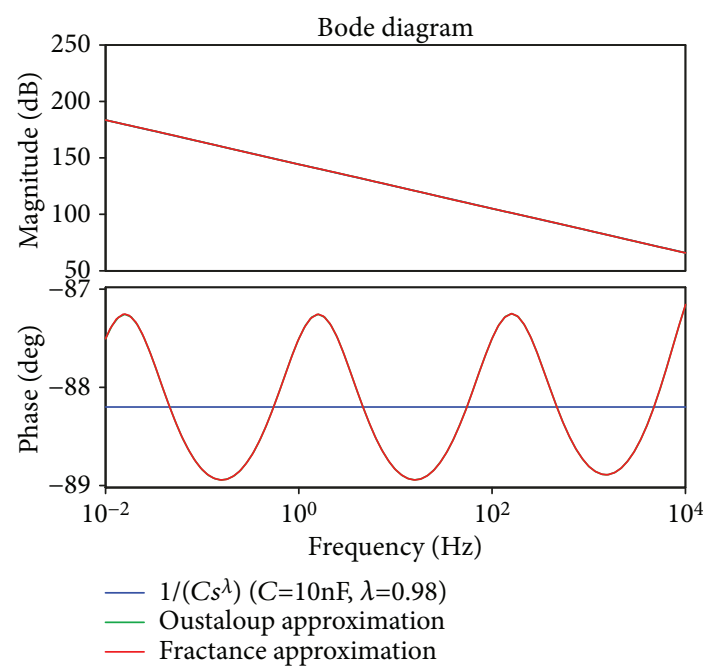

(a)

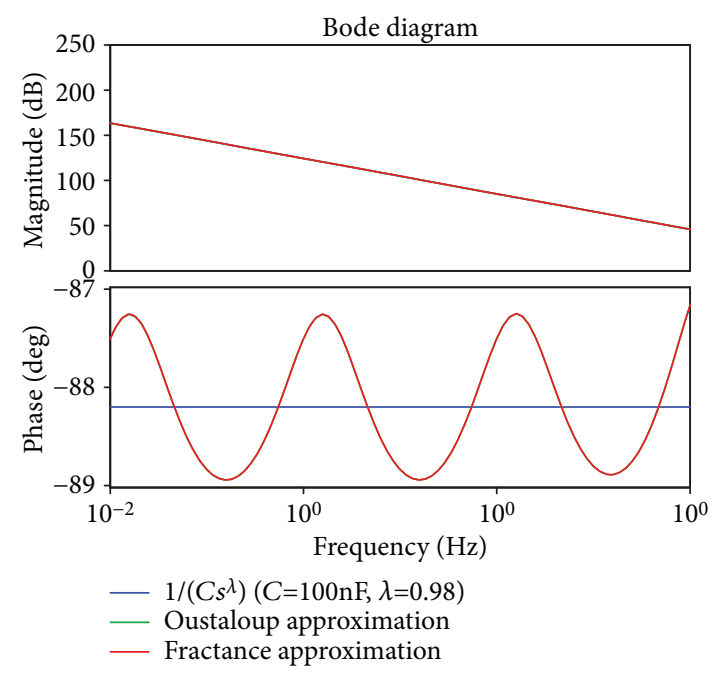

(b)

FIGURE 13: Bode diagram of Oustaloup approximation and fractance circuit approximation.

TABle 5: The resistance parameters of the equivalent chain circuit of fractional-order inductor.

\begin{tabular}{cccccccc}
\hline$R_{0}(\Omega)$ & $R_{1}(\Omega)$ & $R_{2}(\Omega)$ & $R_{3}(\Omega)$ & $R_{4}(\Omega)$ & $R_{5}(\Omega)$ & $R_{6}(\Omega)$ & $R_{7}(\Omega)$ \\
\hline $8.69 e 4$ & $1.09 e 4$ & 118.80 & 1.30 & $1.43 e-2$ & $1.57 e-4$ & $7.63 e-8$ \\
\hline
\end{tabular}

TABLE 6: The inductance parameters of the equivalent chain circuit of fractional-order inductor.

\begin{tabular}{ccccccc}
\hline$L_{1}(\mathrm{H})$ & $L_{2}(\mathrm{H})$ & $L_{3}(\mathrm{H})$ & $L_{4}(\mathrm{H})$ & $L_{5}(\mathrm{H})$ & $L_{6}(\mathrm{H})$ & $L_{7}(\mathrm{H})$ \\
\hline 0.1045 & 0.1135 & 0.1244 & 0.1364 & 0.1495 & 0.0144 & $3.3868 e 3$ \\
\hline
\end{tabular}

bifurcation and chaos with the change of the order, which indicates the importance of order effects on the dynamic behaviors of the system. In order to verify the aforementioned analysis, the equivalent circuit of the fractionalorder memristive chaotic circuit is presented. The nonlinear elements inductor and capacitor are approximately equivalent through a unit circuit. Using the method of undetermined coefficients to solve circuit parameters, a fractional-order memristor-based equivalent circuit is constructed in PSpice. The results of circuit simulations well confirm the investigation on the fractional-order memristive chaotic circuit both in theoretical and numerical.

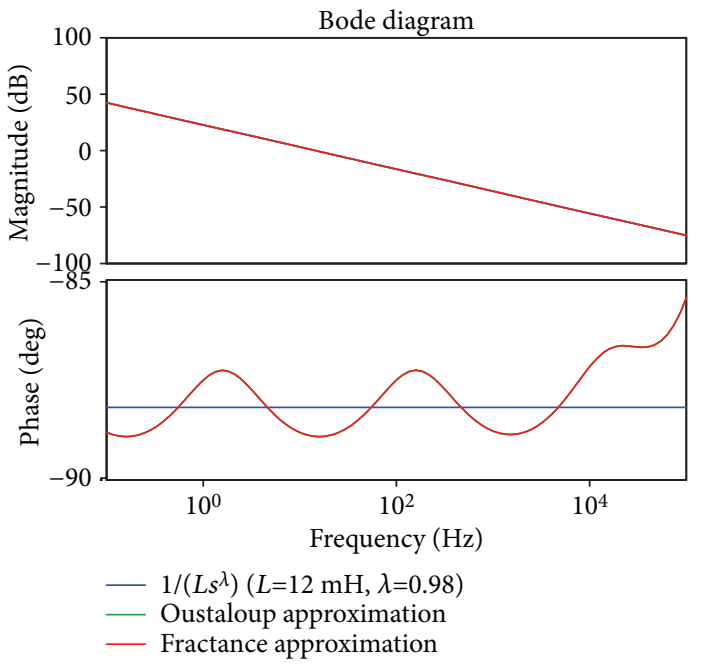

Figure 14: Bode diagram of Oustaloup approximation and fractance circuit approximation. 


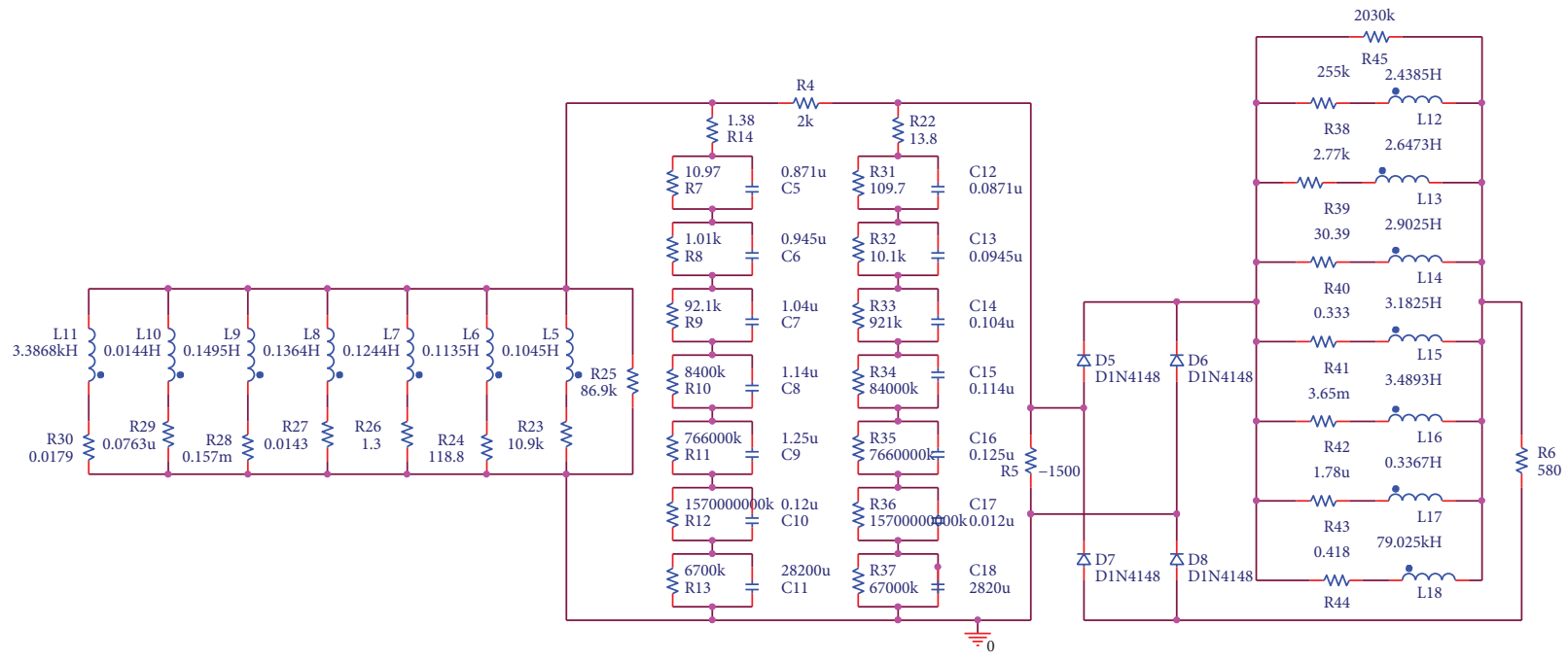

FIGURE 15: The equivalent realization of the fractional-order memristor-based chaotic circuit.

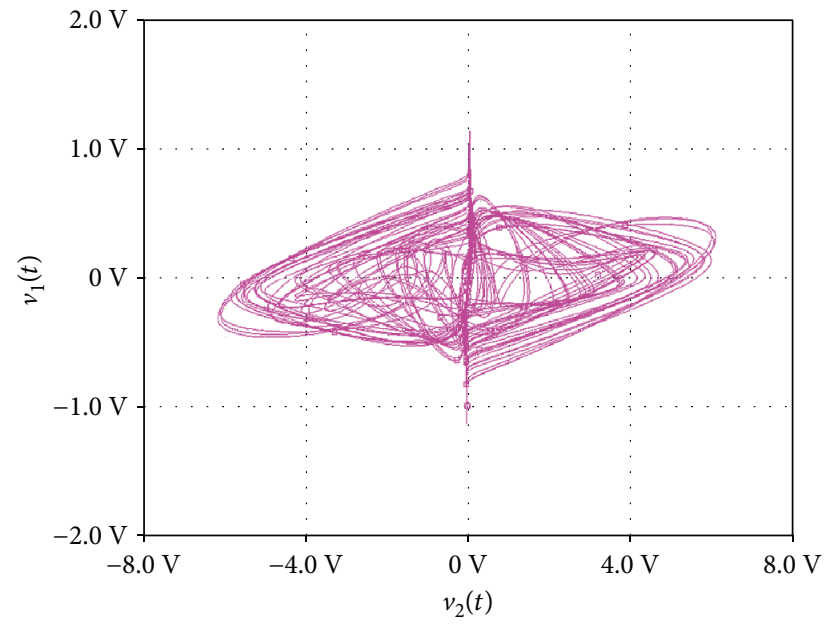

(a)

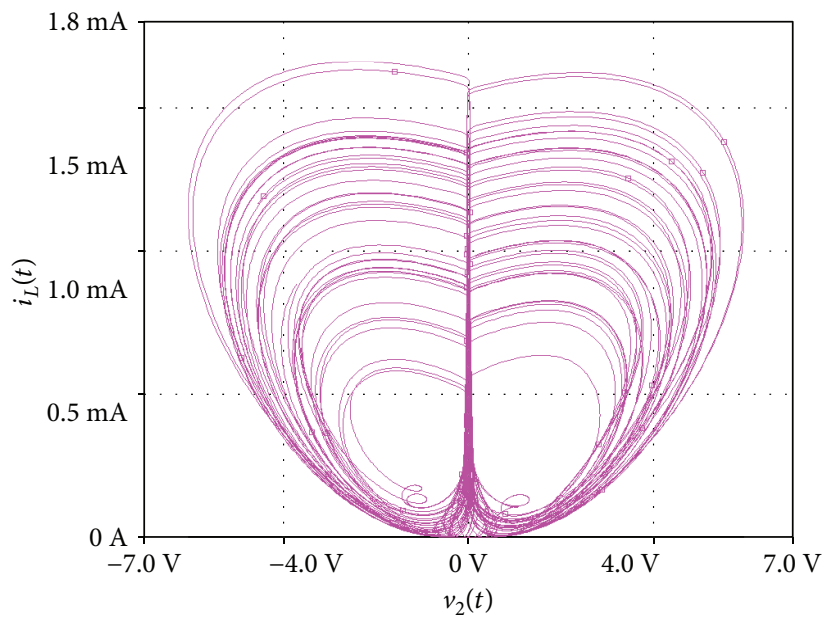

(c)

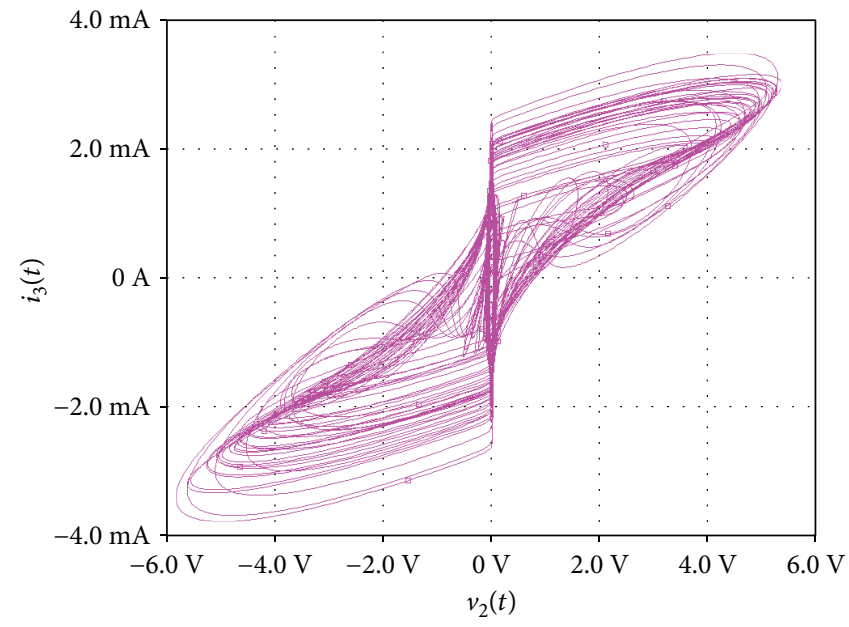

(b)

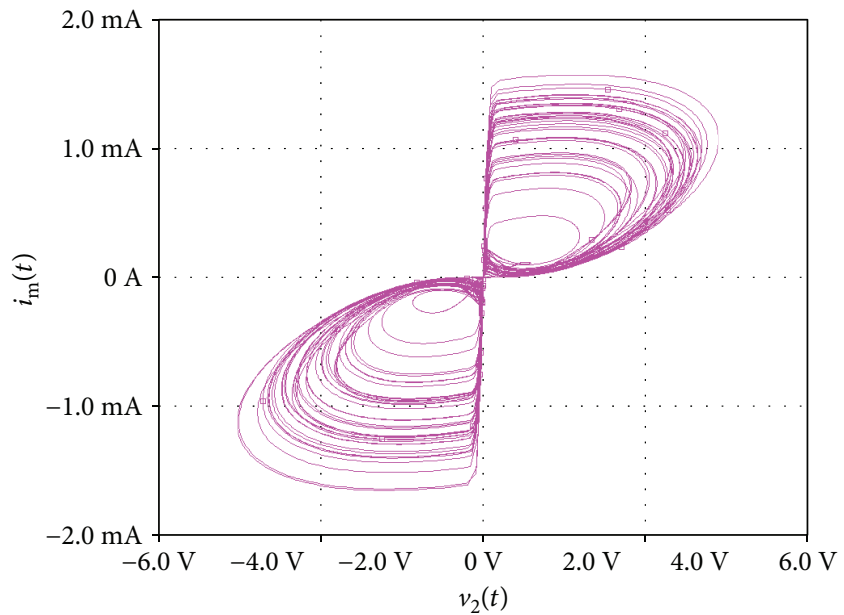

(d)

FIgURE 16: Phase diagrams of the realized fractional-order memristive Chua's circuit. Phase diagrams in the (a) $v_{2}(t)-v_{1}(t)$ plane, $(\mathrm{b})$ $v_{2}(t)-i_{3}(t)$ plane, $(\mathrm{c}) v_{2}(t)-i_{L}(t)$ plane, and $(\mathrm{d}) v_{2}(t)-i_{\mathrm{m}}(t)$ plane. 


\section{Data Availability}

The data used to support the findings of this study are available from the corresponding author upon request.

\section{Conflicts of Interest}

The authors declare that there is no conflict of interest regarding the publication of this paper.

\section{Acknowledgments}

This work was supported by the National Natural Science Foundation of China (Grant No. 51507134), Scientific Research Program Funded by Shaanxi Provincial Department of Water Resources (Grant No. 2017slkj-15), Natural Science Foundation of Shaanxi Province (Grant No. 2018JM5068), Key Project of Natural Science Basic Research Plan in Shaanxi Province of China (Grant No. 2018ZDXMGY-169), and Xi'an Science and Technology Bureau innovation project (Grant No. 201805037 (21)).

\section{References}

[1] L. O. Chua, "Memristor-the missing circuit element," IEEE Transactions on Circuit Theory, vol. 18, no. 5, pp. 507-519, 1971.

[2] M. Di Ventra, Y. V. Pershin, and L. O. Chua, "Circuit elements with memory: memristors, memcapacitors, and meminductors," Proceedings of the IEEE, vol. 97, no. 10, pp. 1717-1724, 2009.

[3] S. P. Mohanty, "Memristor: from basics to deployment," IEEE Potentials, vol. 32, no. 3, pp. 34-39, 2013.

[4] T. D. Dongale, K. P. Patil, S. B. Mullani et al., "Investigation of process parameter variation in the memristor based resistive random access memory (RRAM): effect of device size variations," Materials Science in Semiconductor Processing, vol. 35, pp. 174-180, 2015.

[5] V. Thangamani, "Memristor-based resistive random access memory: hybrid architecture for low power compact memory design," Control Theory \& Informatics, vol. 4, 2014.

[6] A. Thomas, "Memristor-based neural networks," Journal of Physics D: Applied Physics, vol. 46, no. 9, article 093001, 2013.

[7] S. Duan, Z. Dong, X. Hu, L. Wang, and H. Li, "Small-world Hopfield neural networks with weight salience priority and memristor synapses for digit recognition," Neural Computing and Applications, vol. 27, no. 4, pp. 837-844, 2016.

[8] R. Rakkiyappan, A. Chandrasekar, S. Laksmanan, and J. H. Park, "State estimation of memristor-based recurrent neural networks with time-varying delays based on passivity theory," Complexity, vol. 19, no. 4, p. 43, 2014.

[9] B. Mouttet, "Proposal for memristors in signal processing," in International ICST Conference, pp. 11-13, Springer, Berlin, Heidelberg, 2008.

[10] A. M. A. El-Sayed, A. Elsaid, H. M. Nour, and A. Elsonbaty, "Dynamical behavior, chaos control and synchronization of a memristor-based ADVP circuit," Communications in Nonlinear Science and Numerical Simulation, vol. 18, no. 1, pp. 148-170, 2013.

[11] P. Sheridan, W. Ma, and W. Lu, "Pattern recognition with memristor networks," in 2014 IEEE International Symposium on Circuits and Systems, pp. 1078-1081, Melbourne, VIC, Australia, June 2014.
[12] L. Chua, "Everything you wish to know about memristors but are afraid to ask," Radioengineering, vol. 24, no. 2, pp. 319-368, 2015.

[13] F. Corinto and A. Ascoli, "Memristive diode bridge with LCR filter," Electronics Letters, vol. 48, no. 14, pp. 824-825, 2012.

[14] H. Wu, B. Bao, Z. Liu, Q. Xu, and P. Jiang, "Chaotic and periodic bursting phenomena in a memristive Wien-bridge oscillator," Nonlinear Dynamics, vol. 83, no. 1-2, pp. 893-903, 2016.

[15] B. Bao, J. Yu, F. Hu, and Z. Liu, "Generalized memristor consisting of diode bridge with first order parallel RC filter," International Journal of Bifurcation and Chaos, vol. 24, no. 11, article 1450143, 2014.

[16] M. Chen, M. Li, Q. Yu, B. Bao, Q. Xu, and J. Wang, "Dynamics of self-excited attractors and hidden attractors in generalized memristor-based Chua's circuit," Nonlinear Dynamics, vol. 81, no. 1-2, pp. 215-226, 2015.

[17] H. G. Wu, B. C. Bao, and Q. Xu, "First order generalized memristor emulator based on diode bridge and series RL filter," Sexualities, vol. 16, no. 16, pp. 651-664, 2015.

[18] B. C. Bao, P. Wu, H. Bao, M. Chen, and Q. Xu, "Chaotic bursting in memristive diode bridge-coupled Sallen-Key lowpass filter," Electronics Letters, vol. 53, no. 16, pp. 1104-1105, 2017.

[19] Q. Xu, Q. Zhang, N. Wang, H. Wu, and B. Bao, “An improved memristive diode bridge-based band pass filter chaotic circuit," Mathematical Problems in Engineering, vol. 2017, Article ID 2461964, 11 pages, 2017.

[20] M. Itoh and L. O. Chua, "Memristor oscillators," International Journal of Bifurcation and Chaos, vol. 18, no. 11, pp. 31833206, 2008.

[21] B. Muthuswamy and P. P. Kokate, "Memristor-based chaotic circuits," IETE Technical Review, vol. 26, no. 6, pp. 417-429, 2009.

[22] B. Muthuswamy, "Implementing memristor based chaotic circuits," International Journal of Bifurcation and Chaos, vol. 20, no. 5, pp. 1335-1350, 2010.

[23] B. Bao, Z. Ma, J. Xu, Z. Liu, and Q. Xu, "A simple memristor chaotic circuit with complex dynamics," International Journal of Bifurcation and Chaos, vol. 21, no. 9, pp. 2629-2645, 2011.

[24] R. Wu and C. Wang, "A new simple chaotic circuit based on memristor," International Journal of Bifurcation and Chaos, vol. 26, no. 9, article 1650145, 2016.

[25] L. Teng, H. H. C. Iu, X. Wang, and X. Wang, "Chaotic behavior in fractional-order memristor-based simplest chaotic circuit using fourth degree polynomial," Nonlinear Dynamics, vol. 77, no. 1-2, pp. 231-241, 2014.

[26] K. Rajagopal, L. Guessas, A. Karthikeyan, A. Srinivasan, and G. Adam, "Fractional order memristor no equilibrium chaotic system with its adaptive sliding mode synchronization and genetically optimized fractional order PID synchronization," Complexity, vol. 2017, Article ID 1892618, 19 pages, 2017.

[27] L. Zou, Y. Peng, Y. Feng, and Z. Tu, "Stabilization and synchronization of memristive chaotic circuits by impulsive control," Complexity, vol. 2017, Article ID 5186714, 10 pages, 2017.

[28] I. Petras, Y. Q. Chen, and C. Coopmans, "Fractional-order memristive systems," in 2009 IEEE Conference on Emerging Technologies \& Factory Automation, pp. 1-8, Mallorca, Spain, September 2009.

[29] I. Petras and Y. Q. Chen, "Fractional-order circuit elements with memory," in Proceedings of the 13th International Carpathian Control Conference (ICCC), pp. 552-558, High Tatras, Slovakia, May 2012. 
[30] I. Petras, "Fractional-order memristor-based Chua's circuit," IEEE Transactions on Circuits and Systems II: Express Briefs, vol. 57, no. 12, pp. 975-979, 2010.

[31] N. Yang, C. Xu, C. Wu, R. Jia, and C. Liu, "Modeling and analysis of a fractional-order generalized memristor-based chaotic system and circuit implementation," International Journal of Bifurcation and Chaos, vol. 27, no. 13, article 1750199, 2017.

[32] K. B. Oldham and J. Spanier, "The fractional calculus," Mathematical Gazette, vol. 56, no. 247, pp. 396-400, 1974.

[33] I. Podlubny, "Fractional differential equations," in vol. 198 of Mathematics in Science and Engineering, Academic Press, San Diego, CA, USA, 1999.

[34] T. T. Hartley and C. F. Lorenzo, "The error incurred in using the caputo-derivative Laplace-transform," in Volume 4: 7th International Conference on Multibody Systems, Nonlinear Dynamics, and Control, Parts A, B and C, pp. 271-278, San Diego, California, USA, August-September 2009.

[35] F. Z. Wang, L. Shi, H. Wu, N. Helian, and L. O. Chua, "Fractional memristor," Applied Physics Letters, vol. 111, no. 24, article 243502, 2017.

[36] I. Podlubny, I. Petráš, B. M. Vinagre, P. O'Leary, and L. Dorčák, "Analogue realizations of fractional-order controllers," Nonlinear Dynamics, vol. 29, no. 1/4, pp. 281-296, 2002.

[37] N. Heymans and I. Podlubny, "Physical interpretation of initial conditions for fractional differential equations with Riemann-Liouville fractional derivatives," Rheologica Acta, vol. 45, no. 5, pp. 765-771, 2006.

[38] M.-S. Abdelouahab, R. Lozi, and L. Chua, "Memfractance: a mathematical paradigm for circuit elements with memory," International Journal of Bifurcation and Chaos, vol. 24, no. 9, article 1430023, 2014.

[39] S. P. Adhikari, M. P. Sah, H. Kim, and L. O. Chua, "Three fingerprints of memristor," IEEE Transactions on Circuits and Systems I: Regular Papers, vol. 60, no. 11, pp. 3008-3021, 2013.

[40] A. Oustaloup, F. Levron, B. Mathieu, and F. M. Nanot, "Frequency-band complex noninteger differentiator: characterization and synthesis," IEEE Transactions on Circuits and Systems I: Fundamental Theory and Applications, vol. 47, no. 1, pp. 25-39, 2000.

[41] T. Freeborn, Design and Implementation of Fractional Step Filters, Diss. University Of Calgary, 2010. 


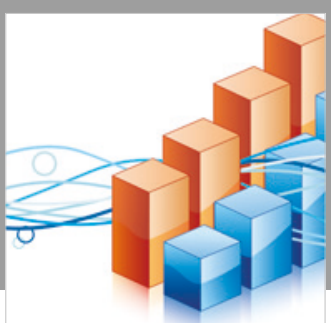

Advances in

Operations Research

\section{-n-m}
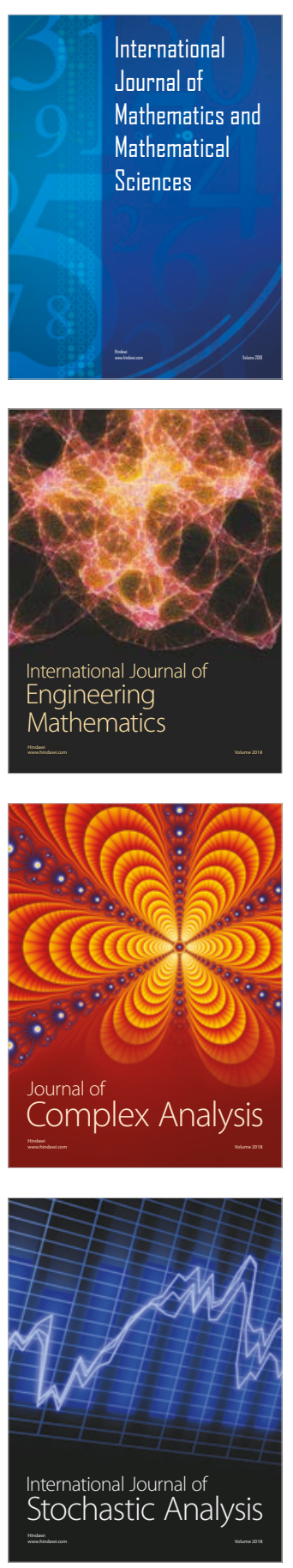
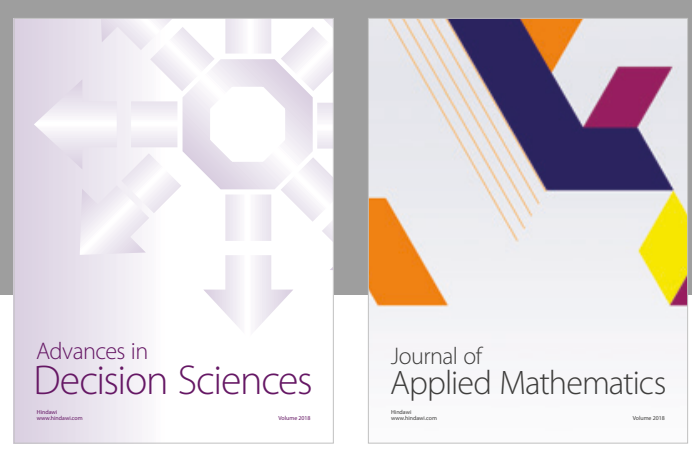

Journal of

Applied Mathematics
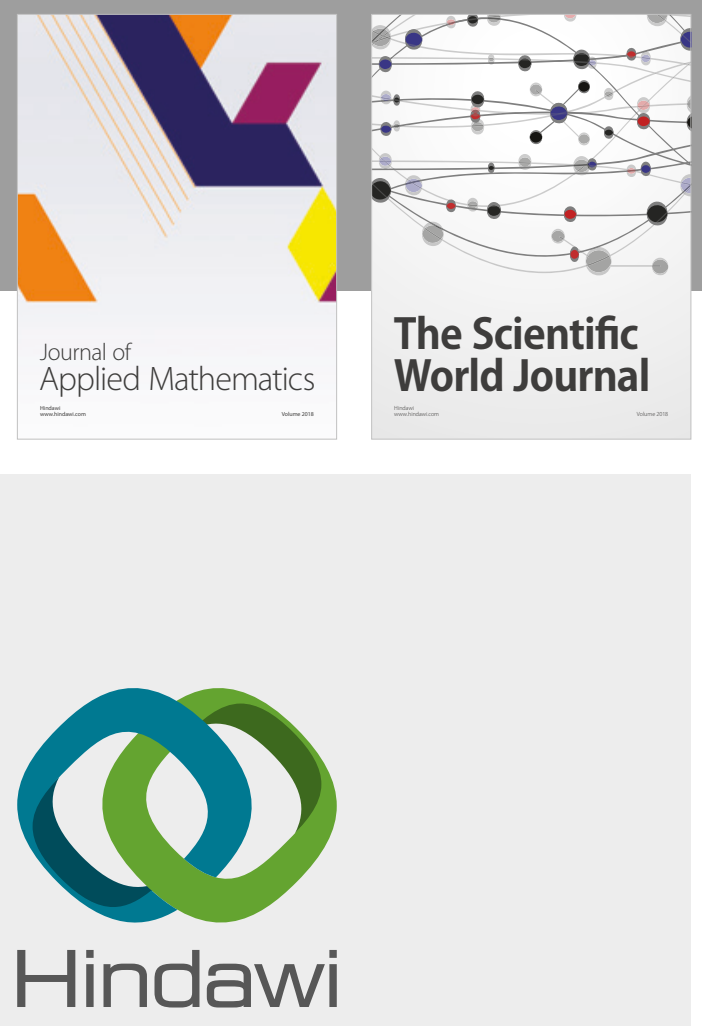

Submit your manuscripts at

www.hindawi.com

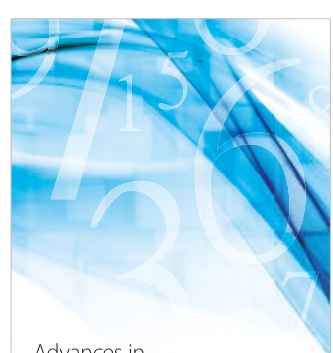

Advances in
Numerical Analysis
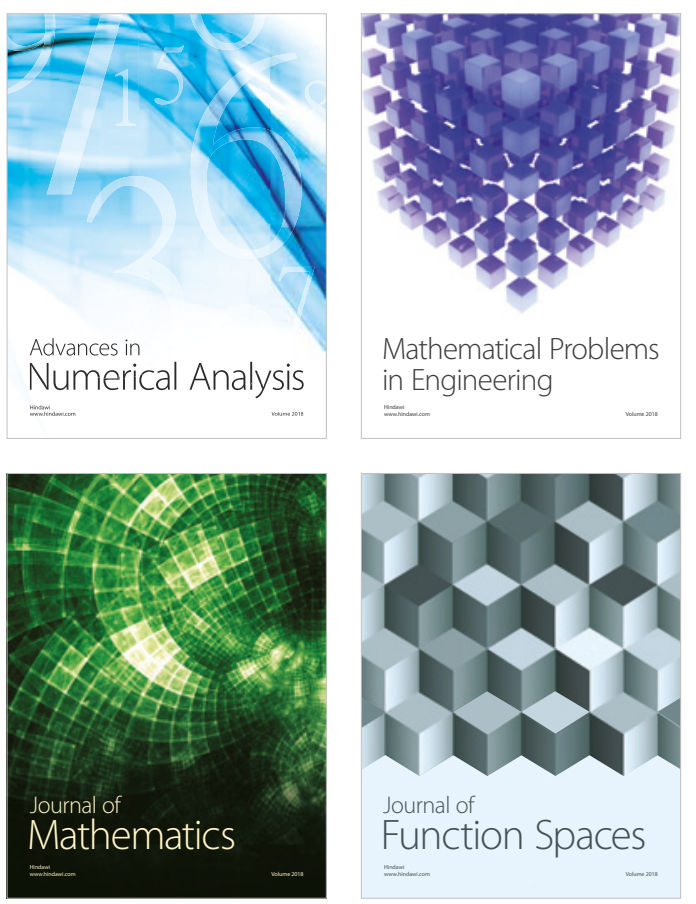

Mathematical Problems in Engineering

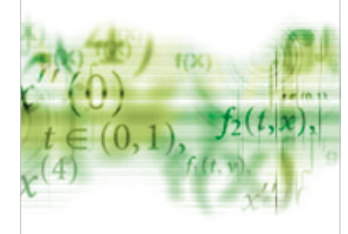

International Journal of

Differential Equations

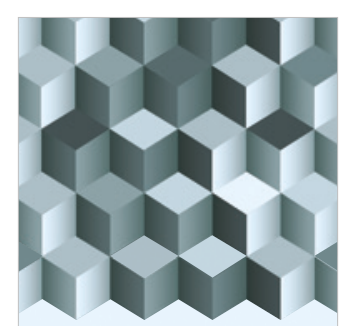

Journal of

Function Spaces
The Scientific

World Journal

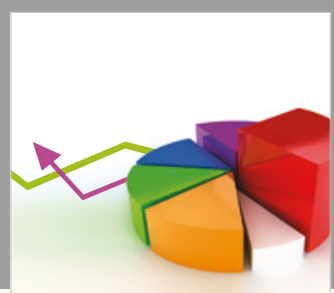

Journal of

Probability and Statistics
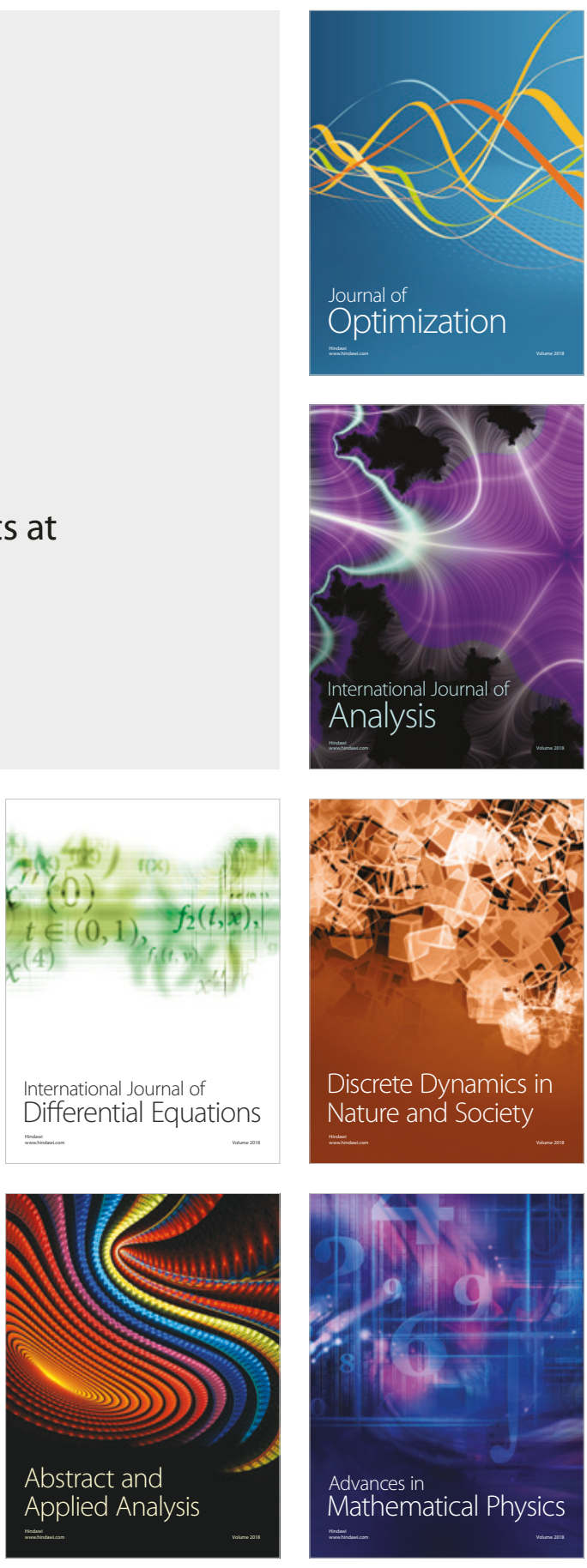